\title{
Risk Factors of Stunting Among Children Aged 6-59 Months In Bensa District ISTRICT, Sidama Region, South Ethiopia: Unmatched Case-Control Study
}

TEMESGEN TAFESSE ( $\nabla$ temesgentfss@gmail.com )

Hawassa University Daye Branch

AMANUEL YOSEPH

Hawassa University

KALEB MAYISO

Hawassa University

TAYE GARI

Hawassa University

\section{Research Article}

Keywords: Children aged 6-59 months, stunting, unmatched case-control, Bensa district, Ethiopia

Posted Date: March 6th, 2021

DOI: https://doi.org/10.21203/rs.3.rs-283465/v1

License: (a) (i) This work is licensed under a Creative Commons Attribution 4.0 International License.

Read Full License 


\section{Abstract}

Background: Stunting remains one of the most common under-nutrition problems among children in the Ethiopia. Children aged $6-59$ months share for $35-45 \%$ of the burden in endemic areas. Identifying the causes of stunting assists health planners to prioritize prevention strategies, and is a fundamental step for intervention. However, evidence scarce about risk factors of stunting among children aged 6-59 months in study area. Therefore, this study aimed to assess risk factors of stunting among children aged 6-59 months in Bensa district, South Ethiopia; 2019.

Methods: A facility-based unmatched case-control study was conducted from January 10 to March 10, 2018 on a sample of 237(79 cases and 158 controls) children aged 6-59 months with their respective mothers. Data were collected using a structured, face-to-face interviewer-administered questionnaire and standard physical measurements. The data were entered using EPINFO version 7 and WHO Anthro software version 3.0.1 and analyzed using SPSS version 20. Chi-square $\left(X^{2}\right)$ test was used to determine the overall association between explanatory and outcome variables. The variables were entered to the multivariable model using the backward stepwise regression approach. Multivariable logistic regression analysis was used to identify factors associated with stunting. Adjusted odds ratios (AORs) with a $95 \%$ confidence interval $(\mathrm{Cl})$ were computed to evaluate the presence and strength of associations.

Results: Diarrhea in past two weeks (AOR $=2.71,95 \% \mathrm{Cl}: 1.42-5.16)$ and male sex $(\mathrm{AOR}=2.37,95 \% \mathrm{Cl}$ : 1.224-4.59) were positively associated with stunting. The odds of stunting increased 2.7 times for children who had inappropriate exclusive breast feeding (AOR $=2.07,95 \% \mathrm{Cl}: 1.07-4.01$ ) as compared to those who had the appropriate exclusive breast feeding. Having less than or equal to three under five children in the household (AOR $=2.18,95 \% \mathrm{Cl}$ : 03-4.64), and mothers had no formal education (AOR $=3.28,95 \% \mathrm{Cl}: 1.56-6.924)$ were positively associated with stunting.

Conclusions: Male sex, diarrhea in past two weeks, inappropriate exclusive breast feeding, number of the under five children in the household and mothers had no formal education were major predictors of the stunting. Educating mothers/care takers on Infant and Young Child Feeding practice. Findings support a focus on prevention of diarrhea as part of an overall public health strategy for improving child health and nutrition.

\section{Background}

Malnutrition refers to both under-nutrition and over-nutrition. Under-nutrition is "an imbalance between nutrient requirement and intake, resulting in cumulative deficits of energy, protein or micronutrients that may negatively affect growth, development and other relevant outcomes. It is often characterized as acute or chronic [1].

Chronic under-nutrition or stunting reflects a process of failure to reach linear growth potential. It is defined as a height/length for age is less than - 2 SD of the median of the NCHS/WHO international reference [2]. 
Worldwide, the prevalence of stunting is very high. Its implication in terms of public health is serious. According to the WHO/UNICEF joint report, it was estimated that 154.8 million children had stunted, 15 million children were suffering from the most severe form of stunting and 3.5-5 million annual deaths occurred among children aged6-59 months [3]. The economic cost of stunting is high which leads total loss of $15 \%$ disability-adjusted life years [4]. It has also resulted in loss of adult height by $1 \%$. Consequently, childhood stunting might end up with $1.4 \%$ losses in productivity [5].

The burden of under-nutrition is a major public health problem in developing countries (Africa and South Asia) which accounts two-third of burden [6]. It is also highly prevalent problem in Ethiopia. According to Ethiopian DHS 2016 report, 38 \% of under-five children were stunted. Similarly, high prevalence reported in South Region, Ethiopia $38.6 \%$ [7].

Under-nutrition is responsible for more than one-third of child deaths and $11 \%$ of the global total diseases burden [8]. It is also responsible for more than half of all deaths among children in developing countries [9]. Whereas $42 \%$ of death occur in the Africa, and an additional $29 \%$ occur in the Southeast Asia [10]. In Ethiopia it is estimated that $28 \%$ of all causes of child mortality are associated with undernutrition [11].

Health consequences of stunting are delay in physical growth and motor development; lower intellectual quotient (IQ), greater behavioral problems and deficient social skills, and susceptibility to contracting diseases. Later in life it increases risk of being overweight and developing associated chronic diseases such as cardiovascular disease, diabetes, cancer, and mental health disorders [12,13].

Under-nutrition is the results of a long sequence of interlinked events. The most frequently suggested causes of under-nutrition are: Immediate cause, underlying cause and basic cause [14].

Twelve of the 17 Sustainable Development Goals contain indicators that are highly relevant for nutrition, reflecting nutrition is central role in sustainable development. Global nutrition target for 2025 to reduce the number of stunted children by $40 \%$ [15].

Ethiopia had established rural development extension strategies and related programs to address undernutrition problem. The outcomes of initiatives are encouraging but, not sufficient due to lack of coordination among the relevant sectors. In addition, Ethiopia launched an ambitious and revised National Nutrition Plan (NNP) primarily focused on the first 1000 days and accelerated stunting reduction actions. It was also targeted to reduce the prevalence of stunting from 44.4-20\% [16]. However, undernutrition remains one of the child health problem and pose a significant obstacle to achieving better child health outcomes [17].

While the problem of stunting in national and regional level is relatively well-documented. There is limited information on the presence of chronic diarrhea associated with stunting among children aged 6-59 months in Bensa district, Sidama, Region, South Ethiopia. In addition, information is also important because the target for GTP 2 in 2020 and the preparation for the third Growth and transformation plan in 
Ethiopia are fast approaching. Moreover, assessing and identifying the predictors for stunting is important to guide public health planners, policymakers and implementers to plan and design appropriate intervention strategies in order to enhance nutritional status of the children. Therefore, the main aim of this study is to assess presence of chronic diarrhea associated with stunting among children aged 6-59 months in Bensa district, Sidama Region, South Ethiopia.

\section{Methods}

\section{Study area}

The study was carried out in Bensa district, Sidama region, South Ethiopia. The district is located $400 \mathrm{~km}$ from Addis Ababa, the capital of Ethiopia. It is also $131 \mathrm{~km}$ from Hawassa, the capital of Sidama Region. According to the central statistical agency report of Ethiopia, the total population of the district was estimated to be 310,952 ( $8.1 \%$ urban and $91.9 \%$ rural). Of these, $13.94 \%$ were children in the age group of 6-59 months. The district has consists of 03 urban and 34 rural Kebeles (smallest administrative unit of Ethiopia). The health service coverage of the district was $94 \%$. There are one-government primary hospital, 11 health centers and 37 health post. It has also consists of 4 private clinics and 12 pharmacies in the districts. According to the health department report, the distribution of stunting affects almost all Kebeles of the district. Agriculture is the main source of income in the district; inhabitants of the district mainly produce enset, cash crops (coffee) and livestock. The total area of the districts is 732.74 . Astronomically, the district is situated between 6.23-6.88 degrees to the north of equator and 38.74-39.09 degrees to the east. The altitude of the district is 1001-2650 meters above sea level. The climatic conditions of district are $47 \%$ highland, $35 \%$ midland and $18 \%$ lowland. Annual temperature is estimated to be between 12.6 -22.5 degree centigrade. Annual temperature is estimated to be between 12.6 -22.5 degree centigrade. Annual range of rainfall is $900-1450 \mathrm{~mm}$ with average of $1125 \mathrm{~mm}$ [18].

\section{Study design and population}

A facility-based unmatched case control study was carried out in Bensa district from January 10 to March 10, 2018. The source population of this study were all children in age group of 6-59 months and mothers/caregivers who utilized EPI and under-five OPD service in all health facilities. The study population were all selected children in age group of 6-59 months and mothers/caregivers in selected health facilities who have lived with the child at least for 6 months. Those children whose family lived less than 6 months and children who were very sick requiring emergency treatment were excluded from this study.

\section{Sample size determination and sampling technique}

The sample size was calculated by using a double population proportion formula in consideration of the following assumptions. The proportion of control in exposure $14.6 \%$ and cases in exposure $32.4 \%$, level of confidence $95 \%$, power of the study $80 \%$, ratio of controls over cases $2: 1(r=2)$. Thus, the final sample size after adding a 10\% non-response rate is 237 (79 cases and 158 controls). In Bensa district, there is 1 
primary hospital and 11 health centers. One primary Hospital and three Health centers were selected out of eleven health centers by simple random sampling technique (lottery method). The calculated sample size (237) was proportionally allocated to the selected health facilities. A consecutive sampling technique was used to select the study participants until the calculated sample size attained. All children aged 6 to 59 months visiting hospital and health centers during the data collection period were measured for their height. Then, children were categorized as stunted or non-stunted based on calculated z-score value. First, stunted children were identified and then selected as cases. The controls were children aged 6 to 59 months without stunting from the same facility cases where selected.

\section{Study variables and data collection technique}

The outcome variable was stunting. The independent variables were: socio-demographic variables such as marital status, residence, ethnicity, religion, number of under-five children, family size, parent's education status, occupation, and economic status: Child characteristics like age, sex, birth order, birth interval, place of delivery, types of birth, and morbidly status (fever, diarrhea and ARI): Child caring practices; such as feeding and immunization: maternal characteristics such as age, mothers' age during first child, number of children ever has born, ANC visits, use of extra food during pregnancy or lactation and family planning: environmental Health condition like water, hygiene and sanitation.

The data collection was administered by 9 Bsc nurses. One health officer and the principal investigator intensively supervised the data collection process. The anthropometric data of children were collected by using the measurement of age and height/length. Height was measured using a measuring board by appropriately trained nurses and the child's head, shoulders, buttocks, knees and heels touched the board. Data collection was conducted in a stepwise manner in each health facility in their respective schedule. Measurement of height was done without shoes; to the nearest $0.1 \mathrm{~cm}$. The raw anthropometric data of the studied children were converted to nutritional indicators using WHO Anthro Software (HFA) by taking sex into consideration. Accordingly, a low height for age, less than -2 SD of the reference population indicates stunting, while less than -3SD indicates severe stunting [3].

\section{Operational definitions}

Stunting (chronic malnutrition): means HFA is below -2 SD of the reference population while below -3 SD indicates severe stunting.

Acute Respiratory illness: child with cough and fast breathing or difficulty in breathing.

Duration of breastfeeding: the number of months of breastfeeding among children.

Pre-lacteal feeding: a child had given anything to drink other than breast milk in the first three days after delivery.

Complementary foods: are foods which are required by the child, after six months of age, in addition to sustained breastfeeding. 
Diarrhea: a child with loose stools for three or more times in a day.

Family size: refers total number of people living in a house during the study period.

Fever: a child with elevated body temperature than usual.

\section{Data quality control}

Data were collected using a structured, face-to-face interviewer-administered questionnaire and standard physical measurements. Firstly, the questionnaire was prepared in English. Secondly, it was translated into Sidama language. Finally, it was retranslated back to English to keep its consistency. The comparison was done to assess the inconsistency and non-accuracy between the two versions of the questionnaire. It was pre-tested on $5 \%$ of samples in health facility other than actual study area. Then, any inconsistency and non-accuracy was corrected accordingly. Training was given for data collectors and supervisors by the principal investigator for two days. The training was focused on the objective, methods and data collection process. Regular checkup for completeness and consistency of the data were made on a daily basis.

\section{Data processing and analysis}

The data were entered into EPINFO version 7 and WHO Anthro software and analyzed using SPSS version 20. Wealth index was constructed by using Principal Components Analysis in SPSS. All required variables recoding and computations were done prior to the main analysis. Descriptive analyses were conducted to obtain descriptive measures for the socio-demographic characteristics and other variables. Chisquare $\left(\mathrm{X}^{2}\right)$ test was used to determine the overall association between explanatory and outcome variables. Cross tabulation was used to test the assumption of $\mathrm{X}^{2}$.

Binary logistic regression was used to identify predictors of stunting. The bi-variable logistic regression analysis started with unadjusted analysis in which each potential predictor was assessed separately for its association with stunting. Variables with $p$-values $<0.25$ on the unadjusted analysis were entered into a multivariable logistic regression model to find out independent predictors of stunting adjusting for other factors in the model. The variables were entered into the multivariable model using the backward stepwise regression approach. The main assumptions of the logistic regression model (absence of outlier, multicollinearity and interaction among independent variables) were checked to be satisfied. Accordingly, none of the interaction terms was statistically significant indicating absence of a significant effect modification. Multicollinearity between the independent variables was also assessed using multiple linear regression. No evidence of multicollinearity was found as the variance inflation factor (VIF) for all variables was less than 5 and the tolerance statistic was greater than 0.1 . The fitness of the logistic regression model was also evaluated in the model using the Hosmer-Lemeshow statistic and greater than 0.05 . The presence and strength of association between stunting and the predictors were assessed using adjusted odds ratios (AORs) with a 95\% Cls. A statistically significant association was declared when the $95 \% \mathrm{Cl}$ of the AOR did not contain1. 


\section{Ethical considerations}

Ethical clearance was obtained from the Institutional Review Board (IRB) at the College of Medicine and Health Sciences of Hawassa University before commencing data collection (Ref. No: IRB/145/11). An official letter of permission was obtained from the Department of Public Health to the respective district health office. Informed written permission was also obtained from district health office. Informed written consent and child assent was also obtained from each study participant after explaining the objectives, risks/benefits, rights, confidentiality, nature of the study and the scope of their involvement in the study.

\section{Results}

\section{Socio-demographic characteristics of the parents}

Socio-demographic characteristics of the parents have been summarized in Table 1.

A total of 237 participants were participated in the study with a response rate of $100 \%$. The majority of study subjects were Sidama in both group; $75(94.9 \%)$ of cases and $154(97.5 \%)$ of controls. Similarly 74 (93.7\%) mothers of children in cases and 151 (95.6\%) in controls were protestant in religion. Mothers of $45(57.0 \%)$ of cases and $48(30.4 \%)$ controls had no formal education. There was significant variation between cases and controls in relation to maternal educational status $(P=0.001)$. Household who had less than or equal to three under five children were $40(50.6 \%)$ and $47(29.7 \%)$ of cases and controls respectively. There was significant difference between cases and controls in relation to the number of under five children in the household $(P=0.002)$. Similarly family size was five and above for $46(58.2 \%)$ of cases and $70(44.3 \%)$ of controls. There was significant variation among cases and controls in relation to the household family size $(P=0.043)$ (Table 1$)$. 
Table 1

Comparison of socio-demographic characteristics between cases and controls in Bensa district, South Ethiopia, 2019

\begin{tabular}{|c|c|c|c|c|c|c|}
\hline \multirow[t]{2}{*}{ Variables Category } & & \multicolumn{2}{|c|}{ Cases $(n=79)$} & \multicolumn{2}{|c|}{ Controls $(n=158)$} & \multirow{2}{*}{$\begin{array}{l}\mathrm{P}- \\
\text { value }\end{array}$} \\
\hline & & Frequency & $\%$ & Frequency & $\%$ & \\
\hline \multirow[t]{2}{*}{ Religion } & Protestant & 74 & 93.7 & 151 & 95.6 & \multirow[t]{2}{*}{.530} \\
\hline & Others & 5 & 6.3 & 7 & 4.4 & \\
\hline \multirow[t]{2}{*}{ Ethnicity } & Sidama & 75 & 94.9 & 154 & 97.5 & \multirow[t]{2}{*}{.309} \\
\hline & Others & 4 & 5.1 & 4 & 2.5 & \\
\hline \multirow[t]{2}{*}{ Residence } & Rural & 66 & 83.5 & 120 & 75.9 & \multirow[t]{2}{*}{.180} \\
\hline & Urban & 13 & 16.5 & 38 & 24.1 & \\
\hline \multirow[t]{2}{*}{ Household head } & Father & 52 & 65.5 & 72 & 45.6 & \multirow[t]{2}{*}{.360} \\
\hline & Mother & 27 & 34.2 & 86 & 54.4 & \\
\hline \multirow[t]{2}{*}{ Marital status } & Married & 73 & 92.4 & 150 & 94.9 & \multirow[t]{2}{*}{.436} \\
\hline & Others & 6 & 7.0 & 8 & 5.1 & \\
\hline \multirow[t]{2}{*}{ Family size } & $<5$ & 33 & 41.8 & 88 & 55.7 & \multirow[t]{2}{*}{.043} \\
\hline & $\geq 5$ & 46 & 58.2 & 70 & 44.3 & \\
\hline \multirow{2}{*}{$\begin{array}{l}\text { Number of }<5 \text { year } \\
\text { children }\end{array}$} & 1 & 39 & 49.4 & 111 & 70.3 & \multirow[t]{2}{*}{.002} \\
\hline & $2-3$ & 40 & 50.6 & 47 & 29.7 & \\
\hline \multirow[t]{4}{*}{$\begin{array}{l}\text { Educational status of } \\
\text { mother }\end{array}$} & $\begin{array}{l}\text { Has no formal } \\
\text { education }\end{array}$ & 45 & 57.0 & 48 & 30.4 & \multirow[t]{4}{*}{.001} \\
\hline & Can read and write & 9 & 11.4 & 11 & 7.0 & \\
\hline & Primary (1-8) & 13 & 16.4 & 72 & 45.6 & \\
\hline & Secondary \& above & 12 & 15.2 & 27 & 17.1 & \\
\hline $\begin{array}{l}\text { Educational status of } \\
\text { father }\end{array}$ & $\begin{array}{l}\text { Has no formal } \\
\text { education }\end{array}$ & 14 & 17.7 & 18 & 11.4 & .130 \\
\hline Mother's occupation & Can read and write & 12 & 15.2 & 15 & 9.5 & \\
\hline \multirow[t]{4}{*}{ Father's occupation } & Primary(1-8) & 34 & 43.0 & 67 & 42.4 & \\
\hline & Secondary \& above & 19 & 24.0 & 58 & 36.7 & \\
\hline & House wives & 66 & 83.5 & 134 & 84.8 & \multirow[t]{2}{*}{.800} \\
\hline & Others & 13 & 16.5 & 24 & 15.2 & \\
\hline
\end{tabular}




\begin{tabular}{|c|c|c|c|c|c|c|}
\hline & Farmers & 57 & 72.2 & 96 & 60.8 & \multirow[t]{2}{*}{.084} \\
\hline & Others & 22 & 27.8 & 62 & 39.2 & \\
\hline \multirow{3}{*}{$\begin{array}{l}\text { Economic status of } \\
\text { families }\end{array}$} & Poor & 41 & 51.9 & 53 & 33.5 & \multirow[t]{3}{*}{.008} \\
\hline & Medium & 17 & 21.5 & 32 & 20.3 & \\
\hline & Rich & 21 & 26.6 & 73 & 46.2 & \\
\hline
\end{tabular}

\section{Child characteristics}

The mean age of cases and controls was 27.35 ( \pm 12.71$)$ and $28.70( \pm 13.27)$ months respectively. The largest proportion of cases $(30.4 \%)$ and controls (27.8\%) of the children were found in 12-23 months age groups. The difference between cases and controls were not significant in relation to child age $(P=$ 0.993). Among the cases, $65.8 \%$ were male and $45.6 \%$ were females. There was significant variation among cases and controls in relation to their child sex $(P=0.003)$. More than half $(54.4 \%)$ of cases and $67.1 \%$ controls were delivered at the health facility. There was no significant variation among cases and controls in relation to the place of delivery $(P=0.057)$. Among the study participants $44(55.7 \%)$ of cases and $51(32.3 \%)$ of controls had diarrhea in the past 2 weeks before the survey. There was significant difference between cases and controls in relation to diarrhea $(P=0.001)$ (Table 2). 
Table 2

Comparison of children characteristics between cases and controls in Bensa district, South Ethiopia, 2019

\begin{tabular}{|c|c|c|c|c|c|c|}
\hline \multirow[t]{2}{*}{ Variables } & \multirow[t]{2}{*}{ Category } & \multicolumn{2}{|c|}{ Cases $(n=79)$} & \multicolumn{2}{|c|}{ Controls $(n=158)$} & \multirow[t]{2}{*}{ P-value } \\
\hline & & Frequency & $\%$ & Frequency & $\%$ & \\
\hline \multirow[t]{2}{*}{ Sex of children } & Male & 52 & 65.8 & 72 & 45.6 & \multirow[t]{2}{*}{.003} \\
\hline & Female & 27 & 34.2 & 86 & 54.4 & \\
\hline \multirow[t]{5}{*}{ Age in months } & $6-11$ & 7 & 8.9 & 16 & 10.1 & \multirow[t]{5}{*}{.993} \\
\hline & $12-23$ & 24 & 30.4 & 44 & 27.8 & \\
\hline & $24-35$ & 20 & 25.3 & 40 & 25.3 & \\
\hline & $36-47$ & 19 & 24.1 & 40 & 25.3 & \\
\hline & $48-59$ & 9 & 11.4 & 18 & 11.4 & \\
\hline \multirow[t]{3}{*}{ Birth order } & 1 & 19 & 24.1 & 61 & 38.6 & \multirow[t]{3}{*}{.003} \\
\hline & $2-3$ & 27 & 34.2 & 63 & 39.9 & \\
\hline & $\geq 4$ & 33 & 41.8 & 34 & 21.5 & \\
\hline \multirow[t]{2}{*}{ Place of delivery } & Home & 36 & 45.6 & 52 & 32.9 & \multirow[t]{2}{*}{.057} \\
\hline & Health facility & 43 & 54.4 & 106 & 67.1 & \\
\hline \multirow[t]{2}{*}{ Home delivery by } & TBA & 6 & 16.7 & 7 & 13.5 & \multirow[t]{2}{*}{.677} \\
\hline & Neighbors & 30 & 83.3 & 45 & 86.5 & \\
\hline \multirow[t]{2}{*}{ Birth type } & Single & 78 & 98.7 & 155 & 98.1 & \multirow[t]{2}{*}{.721} \\
\hline & Multiple & 1 & 1.3 & 3 & 1.9 & \\
\hline \multirow[t]{3}{*}{ Birth interval } & $<2$ year & 19 & 24.1 & 25 & 15.8 & \multirow[t]{3}{*}{.013} \\
\hline & $\geq 2$ & 47 & 59.5 & 79 & 50.0 & \\
\hline & No previous birth & 13 & 16.5 & 54 & 34.2 & \\
\hline \multirow[t]{2}{*}{ Diarrhea, last 2wks } & No & 35 & 44.3 & 107 & 67.7 & \multirow[t]{2}{*}{.001} \\
\hline & Yes & 44 & 55.7 & 51 & 32.3 & \\
\hline \multirow[t]{2}{*}{ Fever, last 2wks } & No & 47 & 59.5 & 113 & 71.5 & \multirow[t]{2}{*}{.062} \\
\hline & Yes & 32 & 40.5 & 45 & 28.5 & \\
\hline \multirow[t]{2}{*}{ ARI, last 2wks } & No & 72 & 91.1 & 134 & 84.8 & \multirow[t]{2}{*}{.173} \\
\hline & Yes & 7 & 8.9 & 24 & 15.2 & \\
\hline
\end{tabular}




\section{Child care practices}

Of all mothers of children in the cases group, 50 (63.3\%) and in the controls group, 118(74.7\%) started breastfeeding within the first one hour after birth. The exclusive breast feeding rate for 6 months were 34 (43.0\%) and 106 (67.1\%) for cases and controls respectively. There was significant variation between cases and controls on duration of exclusive breast feeding $(P=0.001)$. Meanwhile, the duration of breast feeding was less than 2 years for $46(58.2 \%)$ and 86 (54.4\%) of cases and controls respectively. Concerning immunization status $67(84.4 \%)$ of cases and $146(92.4 \%)$ of controls were vaccinated, and $35(44.3 \%)$ of cases and $90(57.0 \%)$ of controls were received deworming services. There was no significant difference between cases and controls in relation to being immunized $(P=0.066)$ (Table 3$)$. 
Table 3

Comparison of child care practices between cases and controls in Bensa district, South Ethiopia, 2019

\begin{tabular}{|c|c|c|c|c|c|c|}
\hline \multirow[t]{2}{*}{ Variables } & \multirow[t]{2}{*}{ Category } & \multicolumn{2}{|c|}{ Cases $(n=79)$} & \multicolumn{2}{|c|}{ Controls $(\mathrm{n}=158)$} & \multirow{2}{*}{$\begin{array}{l}\text { P- } \\
\text { value }\end{array}$} \\
\hline & & Frequency & $\%$ & Frequency & $\%$ & \\
\hline \multirow{2}{*}{$\begin{array}{l}\text { Breast milk initiated after } \\
\text { delivery }\end{array}$} & Immediately & 50 & 63.3 & 118 & 74.7 & \multirow[t]{2}{*}{.069} \\
\hline & After 1 to $24 \mathrm{hr}$ & 29 & 36.7 & 40 & 25.3 & \\
\hline \multirow[t]{2}{*}{ Pre-lactation food/fluid } & No & 69 & 87.3 & 136 & 86.1 & \multirow[t]{2}{*}{.788} \\
\hline & Yes & 10 & 12.7 & 22 & 13.9 & \\
\hline \multirow{2}{*}{$\begin{array}{l}\text { Type of pre-lactation } \\
\text { food/fluid }\end{array}$} & Water & 5 & 50 & 10 & 45.5 & \multirow[t]{2}{*}{.811} \\
\hline & Others & 5 & 50 & 12 & 54.5 & \\
\hline \multirow[t]{2}{*}{ Duration of EBF } & $\begin{array}{l}<6 \text { or }> \\
6 \text { months }\end{array}$ & 45 & 57.0 & 52 & 32.9 & \multirow[t]{2}{*}{.001} \\
\hline & 6 months & 34 & 43.0 & 106 & 67.1 & \\
\hline \multirow[t]{2}{*}{ Complimentary Feeding } & $\begin{array}{l}<6 \text { or }> \\
6 \text { months }\end{array}$ & 45 & 57.0 & 52 & 32.9 & \multirow[t]{2}{*}{.001} \\
\hline & 6 months & 34 & 43.0 & 106 & 67.1 & \\
\hline \multirow[t]{3}{*}{ Frequency of feeding/day } & 2 times & 13 & 16.5 & 20 & 12.7 & \multirow[t]{3}{*}{.607} \\
\hline & 3 times & 36 & 45.6 & 69 & 43.7 & \\
\hline & $\geq 4$ times & 30 & 38.0 & 69 & 43.7 & \\
\hline \multirow[t]{3}{*}{ Method used for feeding } & Bottle & 21 & 26.6 & 28 & 17.7 & \multirow[t]{3}{*}{.274} \\
\hline & Hand & 19 & 24.1 & 40 & 25.3 & \\
\hline & Spoon and Cup & 39 & 49.4 & 90 & 57.0 & \\
\hline \multirow[t]{2}{*}{ Duration of $\mathrm{B} / \mathrm{F}$} & $<24$ months & 46 & 58.2 & 86 & 54.4 & \multirow[t]{2}{*}{.579} \\
\hline & $\geq 24$ months & 33 & 41.8 & 72 & 45.6 & \\
\hline \multirow[t]{2}{*}{ Immunization } & No & 12 & 15.2 & 12 & 7.6 & \multirow[t]{2}{*}{.068} \\
\hline & Yes & 67 & 84.4 & 146 & 92.4 & \\
\hline \multirow[t]{2}{*}{ VAS } & No & 15 & 19.0 & 17 & 10.8 & \multirow[t]{2}{*}{.081} \\
\hline & Yes & 64 & 81.0 & 141 & 89.2 & \\
\hline \multirow[t]{2}{*}{ Deworming } & No & 44 & 55.7 & 68 & 43.0 & \multirow[t]{2}{*}{.066} \\
\hline & Yes & 35 & 44.3 & 90 & 57.0 & \\
\hline
\end{tabular}




\section{Maternal characteristics}

The mean age for mothers of the cases was $29.25( \pm 5.88)$ while it was $27.30( \pm 5.17)$ for the mothers of the controls. Mothers of $33(41.8 \%)$ of cases and $40(25.3 \%)$ of controls had given birth of 4 and above children. There was significant difference between cases and controls regards to the parity $(P=0.01)$. Mothers of $52(65.8 \%)$ of cases and $82(51.9 \%)$ of controls didn't consume extra food during pregnancy and lactation. There was significant difference between cases and controls in relation to maternal extra food consumption during pregnancy and lactation $(P=0.041)$.About $62(78.5 \%)$ and $132(83.5 \%)$ of mothers visited health facilities for antenatal care during their pregnancy period for both cases and controls respectively. Concerning family planning, mothers of $61(77.2 \%)$ of cases and $125(79.1 \%)$ of controls were every used family planning (Table 4).

Table 4

Comparison of maternal characteristics between cases and controls in three Bensa district, South Ethiopia, 2019

\begin{tabular}{|c|c|c|c|c|c|c|}
\hline \multirow[b]{2}{*}{ Variables } & \multirow[b]{2}{*}{ Category } & \multicolumn{2}{|c|}{ Cases $(n=79)$} & \multicolumn{2}{|c|}{ Controls $(n=158)$} & \multirow[b]{2}{*}{$\begin{array}{l}\mathrm{P}- \\
\text { value }\end{array}$} \\
\hline & & Frequency & $\%$ & Frequency & $\%$ & \\
\hline \multirow[t]{3}{*}{ Mothers age } & $<20$ years & 7 & 8.9 & 17 & 10.8 & \multirow[t]{3}{*}{.127} \\
\hline & $\begin{array}{l}20-35 \\
\text { years }\end{array}$ & 60 & 75.9 & 130 & 82.3 & \\
\hline & $>35$ years & 12 & 15.2 & 11 & 7.0 & \\
\hline \multirow[t]{2}{*}{ Mothers age during first child } & $<21$ years & 60 & 75.9 & 110 & 69.6 & \multirow[t]{2}{*}{.308} \\
\hline & $\geq 21$ years & 19 & 24.1 & 48 & 30.4 & \\
\hline \multirow[t]{2}{*}{ Number of children } & $<4$ & 46 & 58.2 & 118 & 74.7 & \multirow[t]{2}{*}{.010} \\
\hline & $\geq 4$ & 33 & 41.8 & 40 & 25.3 & \\
\hline \multirow{2}{*}{$\begin{array}{l}\text { Extra food during pregnancy and } \\
\text { lactation }\end{array}$} & No & 52 & 65.8 & 82 & 51.9 & \multirow[t]{2}{*}{.041} \\
\hline & Yes & 27 & 34.2 & 76 & 48.1 & \\
\hline \multirow[t]{2}{*}{ ANC for this child } & No & 17 & 21.5 & 26 & 16.5 & \multirow[t]{2}{*}{.340} \\
\hline & Yes & 62 & 78.5 & 132 & 83.5 & \\
\hline \multirow[t]{2}{*}{ F/P every used } & No & 18 & 22.8 & 33 & 20.9 & \multirow[t]{2}{*}{.737} \\
\hline & Yes & 61 & 77.2 & 125 & 79.1 & \\
\hline
\end{tabular}


Children of households who used unprotected source of water for drinking accounts 32 (40.5\%) and 43 $(27.2 \%)$ in cases and controls respectively. There was significant variation between cases and controls in relation to sources of water $(P=.038)$. Those children households who didn't treat water by any means was found to be $61(77.2 \%)$ in cases and $113(71.5 \%)$ in controls. There was no significant difference between cases and controls regards to water treatment method at home $(P=0.349)$. Majority children of $\mathrm{HHs}, 73(92.4 \%)$ of cases and 148 (93.7\%) of controls have a latrine. There was no significant variation between cases and controls in relation to latrine availability $(P=0.714)($ Table 5$)$.

Table 5

Comparison of WASH conditions between cases and controls in Bensa district, South Ethiopia, 2019

\begin{tabular}{|c|c|c|c|c|c|c|}
\hline \multirow[t]{2}{*}{ Variables } & \multirow[t]{2}{*}{ Category } & \multicolumn{2}{|c|}{ Cases $(n=79)$} & \multicolumn{2}{|c|}{ Controls $(n=158)$} & \multirow{2}{*}{$\begin{array}{l}\mathrm{P}- \\
\text { value }\end{array}$} \\
\hline & & Frequency & $\%$ & Frequency & $\%$ & \\
\hline \multirow[t]{2}{*}{ Drinking water source } & Unprotected & 32 & 40.5 & 43 & 27.2 & \multirow[t]{2}{*}{.038} \\
\hline & Protected & 47 & 59.5 & 115 & 72.8 & \\
\hline \multirow[t]{2}{*}{ Treat water by any means } & No & 61 & 77.2 & 113 & 71.5 & \multirow[t]{2}{*}{.349} \\
\hline & Yes & 18 & 22.8 & 45 & 28.5 & \\
\hline \multirow[t]{2}{*}{ Having latrine } & No & 6 & 7.6 & 10 & 6.3 & \multirow[t]{2}{*}{.714} \\
\hline & Yes & 73 & 92.4 & 148 & 93.7 & \\
\hline \multirow[t]{2}{*}{ Wash hand after toilet } & No & 15 & 19.0 & 39 & 24.7 & \multirow[t]{2}{*}{.324} \\
\hline & Yes & 64 & 81.0 & 119 & 75.3 & \\
\hline \multirow[t]{3}{*}{$\begin{array}{l}\text { Material used to wash hands } \\
\text { after toilet }\end{array}$} & $\begin{array}{l}\text { Using water } \\
\text { only }\end{array}$ & 34 & 53.1 & 55 & 46.2 & \multirow[t]{3}{*}{.096} \\
\hline & $\begin{array}{l}\text { Water and } \\
\text { soap }\end{array}$ & 20 & 31.2 & 54 & 45.4 & \\
\hline & $\begin{array}{l}\text { Water and } \\
\text { ashe }\end{array}$ & 10 & 15.6 & 10 & 8.4 & \\
\hline \multirow[t]{2}{*}{ Flush toilet } & No & 58 & 73.4 & 96 & 60.8 & \multirow[t]{2}{*}{.054} \\
\hline & Yes & 21 & 26.6 & 62 & 39.2 & \\
\hline \multirow{4}{*}{$\begin{array}{l}\text { Method used for disposal of } \\
\text { HHs waste }\end{array}$} & Open field & 16 & 20.3 & 18 & 11.4 & \multirow[t]{4}{*}{.113} \\
\hline & In pit & 16 & 20.3 & 46 & 46 & \\
\hline & Composting & 41 & 51.9 & 74 & 74 & \\
\hline & Burning & 6 & 7.6 & 20 & 20 & \\
\hline
\end{tabular}




\section{Predictors of stunting among children aged 6-59 months}

Multivariable model rivaled that children living in households less than or equal to three under-five children were 2.18 times more odds of developing stunting as compared to those living in households with one under-five child (AOR $=2.18,95 \% \mathrm{Cl}: 1.03-4.64)$. The odds of stunting in male children were 2.4 times higher as compared to female ( $A O R=2.37,95 \%: 1.224-4.59)$.

This model also showed that children whose mothers have no formal education were 3.28 times more odds of stunted as compared to mother with formal education ( $\mathrm{AOR}=3.28,95 \% \mathrm{Cl}: 1.56-6.924)$. Moreover, inappropriately exclusive breast feeding ( $\mathrm{AOR}=2.07,95 \% \mathrm{Cl}: 1.07-4.01)$ and exposure to diarrhea in past 2 weeks (AOR $=2.71,95 \% \mathrm{Cl}: 1.42-5.16)$ were positively associated with stunting (Table 6). 
Table 6

Bi-variable and multivariable logistic regression analysis of the factors associated with stunting among children aged 6-59 months in the Bensa district, South Ethiopia.

\begin{tabular}{|c|c|c|c|c|}
\hline Variables & Cases & Controls & COR(95\%Cl) & AOR(95\%Cl) \\
\hline \multicolumn{5}{|l|}{ Sex of children } \\
\hline Male & 52 & 72 & $2.300(1.313-4.029)^{\star \star}$ & $2.369(1.224-4.586)^{*}$ \\
\hline Female & 27 & 86 & 1 & 1 \\
\hline \multicolumn{5}{|l|}{ Total family size } \\
\hline$\geq 5$ & 46 & 70 & $1.752(1.015-3.036)^{\star}$ & $.492(.174-1.389)$ \\
\hline$<5$ & 33 & 88 & 1 & 1 \\
\hline \multicolumn{5}{|l|}{$\begin{array}{l}\text { Number of }<5 \text { year } \\
\text { children }\end{array}$} \\
\hline - & 40 & 47 & $2.422(1.387-4.230) \star \star$ & $2.182(1.027-4.635) *$ \\
\hline 1 & 39 & 111 & 1 & 1 \\
\hline \multicolumn{5}{|l|}{$\begin{array}{l}\text { Maternal educational } \\
\text { status }\end{array}$} \\
\hline \multirow{2}{*}{ Has no formal education } & 45 & 48 & $3.712(2.041-6.753)^{\star \star \star}$ & $\begin{array}{l}3.279(1.553- \\
6.924) * *\end{array}$ \\
\hline & 9 & 11 & $3.240(1.211-8.669)^{\star}$ & $2.752(.897-8.446)$ \\
\hline Has formal education & 25 & 99 & 1 & 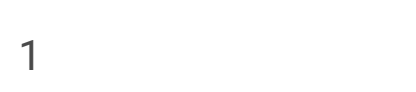 \\
\hline \multicolumn{5}{|l|}{ Wealth Index } \\
\hline Poor & 41 & 53 & $2.689(1.427-5.068)^{\star \star}$ & $1.169(.538-2.539)$ \\
\hline Medium & 17 & 32 & 1.847(.861-3.959) & $.906(.360-2.281)$ \\
\hline Rich & 21 & 73 & 1 & 1 \\
\hline \multicolumn{5}{|l|}{ Diarrhea, preceding $2 w k s$} \\
\hline Yes & 44 & 51 & $2.638(1.514-4.596)^{\star \star}$ & $\begin{array}{l}2.706(1.418- \\
5.162)^{\star \star}\end{array}$ \\
\hline No & 35 & 107 & 1 & 1 \\
\hline \multicolumn{5}{|l|}{ Duration of EBF } \\
\hline$<6$ or $>6$ months & 45 & 52 & $2.698(1.548-4.702)$ & $2.068(1.065-4.011)^{*}$ \\
\hline 6 months & 34 & 106 & 1 & 1 \\
\hline \multicolumn{5}{|c|}{$\begin{array}{l}*: \mathrm{P}<.05 ; \star \star: \mathrm{P}<.005 ; * \star \star \mathrm{P}<.001 ; \text { COR: Crude Odds Ratio; AOR: Adjusted Odds Ratio; Cl: Confidence } \\
\text { Interval; }\end{array}$} \\
\hline 1: Reference category. & & & & \\
\hline
\end{tabular}




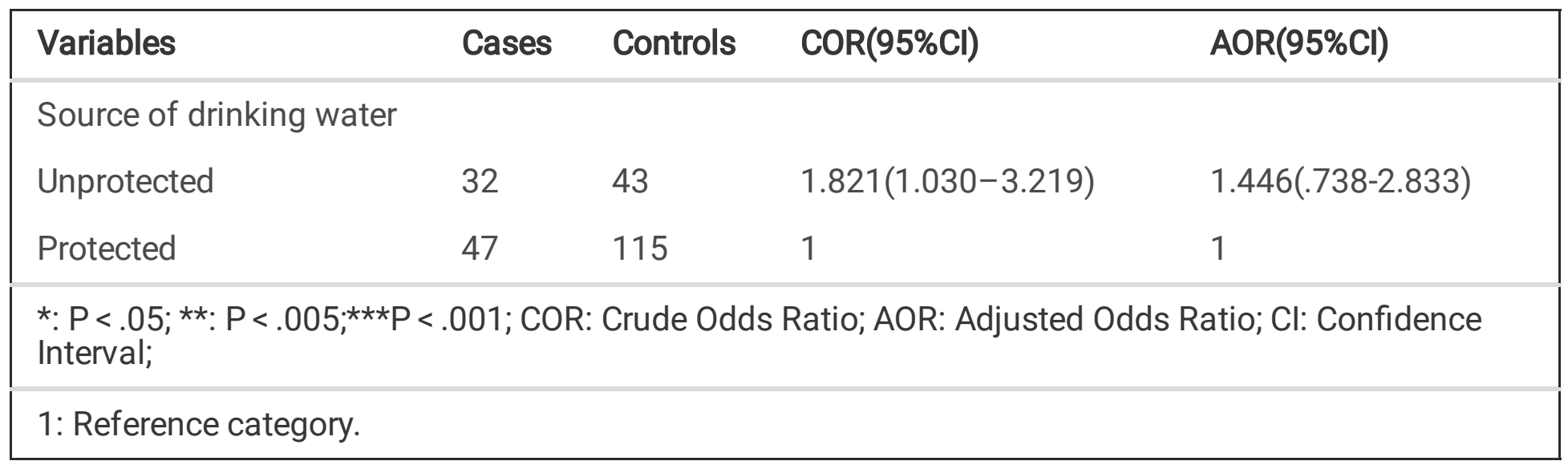

\section{Discussion}

In this study factors associated with stunting were having less than or equal to three under-five children in the household, male sex, mothers who had no formal education, inappropriate exclusive breast feeding, and exposure to diarrheal diseases in the last 2 weeks preceding of the survey.

In this study households with less than or equal to three under-five children is more odds of developing stunting as compared to one under-five child in the house hold. This finding is similar with the studies conducted in south Ethiopia, Mozambique $[19,20]$. This might be the fact that as the number of underfive children increases in the household the care given to the children decreases, mothers unable to optimally breastfeeding children, causes competition on family resources and increases the risk of infectious diseases[21].

The odds of stunting are significantly higher in male children than female. This result is consistent with studies done in Lasta district, and Korahay Zone, Ethiopia, Mozambique and Southwest Uganda [20, 2224]. The cause of this difference in sex requires further study, but variation might be due to sex preference of family. Additionally, it is believed that boys to be biologically more vulnerable to morbidity [25].

Children whose mothers had no formal education were more likely to be stunted as compared to have formal education. This study is in line with studies conducted in Padang city, Indonesia, India, Nairobi, Kenya and Ethiopia [23, 26-28]. Mother's education affects the knowledge and attitude of parents which in turn affect their fertility behavior, use of health service and access of nutrition related information. The cumulative effect of these can have impact on prevention of stunting [29].

Inappropriate exclusive breastfeeding significantly associated with stunting. This result is agreed with study conducted in Nepal, and South Ethiopia $[19,30]$. This could be child's digestive and immune systems are not mature before 6 months, and early introduction of complimentary food in unhygienic condition increases diarrheal disease. Furthermore, after 6 months breast milk alone is not sufficient to meet the nutritional requirements. Both earlier and delayed introduction of complementary food predisposes the child to increased risks of growth faltering [31]. 
Children with diarrhea exposure are at increased risk of stunting compared to those with no exposure. This finding is in line with the finding of studies conducted in South Ethiopia, Kenya [32,33]. This might be due to children with diarrhea may have reduced dietary intake, poor absorption of nutrients and increased nutrient loss.

\section{Limitation Of The Study}

This study had a number of strengths. Among these, many variables considered to be risk factors of stunting were assessed, valid adapted questionnaires from other studies, and pre-tested questioner was used to collect information, and the case control nature of this study is stronger than cross-sectional study in assessing risk factors which is important to develop relevant policy strategy for efficient prevention of stunting. Regardless of its strengths, our study has some basic limitations that might be considered while interpreting the findings. First, the study might be prone to recall bias because, the study was questionnaire based require a good memory of mother's/care giver. Second, the study is predisposed to errors of anthropometric measurement that might lead to misclassification of children's nutritional status.

\section{Conclusion}

Number of under-five year old children in the household, sex of child, mother's educational status, inappropriate exclusive breast feeding and diarrhea in past 2 weeks were significantly associated factors with stunting. Therefore, prevention and control of stunting through improving family planning service utilization should be considered. In addition, intervention should focus on health education for the promotion of appropriate exclusive breast feeding. Moreover, preventing and controlling childhood disease like diarrhea through health extension programs is recommended.

\section{List Of Abbreviations}

AOR

Adjusted odd ratio

$\mathrm{Cl}$ Confidence Interval

GTP 2 ..Growth and transformation plan

$\mathrm{SD}$ Standard Deviation

OR. Odd ratio

SPSS Statistical packages for social science

WASH Water, sanitation and hygiene

WHO World Health Organization 


\section{Declarations}

\section{Acknowledgement}

Authors would like to thank the Hawassa University, School of Public Health for approval of ethical clearance. The authors are also very grateful for data collectors and study participants. Finally, our special thanks go to Nana Chea for his genuine support.

\section{Authors' contributions}

TT- Involved in initiation of the research question, prepared the research proposal, carried out the research, did the data entry and analysis and wrote the manuscript. TG-conducted edition, advising, cooperatively prepared research tools with $\mathrm{PI}$ and revised the manuscript. KM- conducted edition, advising and reviewed the manuscript. AY-Did the data entry, analysis, prepared and reviewed the manuscript. All authors have read and approved the final manuscript.

\section{Funding}

The financial aid of this thesis was obtained from Bensa district with specific grant numbers BWH/10123/10. Temesgen Tafesse is author who received award. The funded agency did not take part in thesis design, data collection and manuscript preparation process.

\section{Availability of data and materials}

The datasets used and/or analyzed during the current study available from the corresponding author on reasonable request.

\section{Ethics approval and consent to participate}

Ethical clearance was obtained from Hawassa University College of Medicine and Health Sciences Institutional Review Board (IRB) and written permission letter was obtained from Bensa Woreda Health Office before official start of the study. The purposes and importance of the study was explained at all levels and written informed consents were secured from each mothers/care takers. All methods were carried out in accordance with relevant guidelines and regulations.

\section{Consent for publication}

Not applicable

\section{Competing interests}

All authors declare that they have no conflicts of interests.

\section{References}


1. Becker P, Mark R, Monczka J, Smith E. Consensus Statement of the Academy of Nutrition and Dietetics/American Society for Parenteral and Enteral Nutrition. 2016;114:12.

2. WHO Expert, and committee. The use and interpitation of Anthropometry. The use and interpitation of Anthropometry, 1195.

3. World Health Organization(WHO)/UNCIFE. Essential nutrition actions: improving maternal, newborn, infant and young child health and nutrition, 2016. World Health Organization(WHO): Geneva, Switzerland.

4. World Health Organization. Comparative Quantification of Health Risks in Global and Regional Burden of Disease Attributable to Selected Major Risk Factors. Majid Ezzati, etal. Editors, 2014. World Health Organization Geneva, swizerland.

5. Joseph M Hunt. The potential impact of reducing global malnutrition on poverty reduction and economic development. Asia Pac J Clin Nutr, 2005.

6. UNICEF/WHO and W. bank. Levels and trends in child malnutrition, Joint Child Malnutrition Estimates, 2016.

7. Centeral Stastic Agency (CSA)[Ethiopia] and I. international, Ethiopia Demographic and Health Survey. 2016.

8. The Lancet's Series on Maternal and Child Undernutrition. The Lancet, 2008.

9. Müller $O$ etal. Malnutrition and health in developing countries. CMAJ, 2005. 173(3): p. 279-86.

10. Bryce J, et al. WHO estimates of the causes of death in children. The Lancet, 2005. 365: p. 1147-52.

11. African Union Commission. World Food Programme, and U.N.E.C.f. Africa. The Cost of Hunger in Africa. 2012.

12. World Health Organization. Nutrition Landscape Information System (NLIS) Country Profile Indicators. WHO Document Production Services, 2010.

13. Black RE, Morris SS, and B. J. Where and why are 10 million children dying every day? The Lancet, 2003. 361: p. 2226-34.

14. UNICEF find approach to scaling up nutrition for mothers and their children. Discussion Paper Programme Division, 2015.

15. Adam smith. Global Nutrition Report 2016 : From Promise to Impact: Ending Malnutrition by 2030. International Food Policy Research Institute, 2016.

16. Federal, Democratic, and R.o. Ethiopia, National Nutrition Programme. 2013.

17. Alemu M, Nicola J. Tackling Child Malnutrition in Ethiopia. Young lives project working, 2005. 9.

18. Sidama Zone Administration. Health and agricultural report annual report, 2013.

19. Fikadu T, Assegid S. Factors associated with stunting among children of age 24 to 59 months in Meskan district, Gurage Zone, South Ethiopia: a case-control study. BMC Public Health, 2014. 14: p. 800.

20. Maria L, et al. Factors Associated with Stunting among Children Aged 0 to 59 Months from the Central Region of Mozambique. Nutrients, 2017. 9: p. 491. 
21. Nair R et al. Linkage between family planning and nutrtion. Futers Group,Health policy Project, 2015.

22. Birhanu A, et al. Stunting and Associated Factors among Children Aged 6-59 Months in Lasta district, North East Ethiopia, 2015: A Community Based Cross Sectional Study Design. Journal of Family Medicine, 2017. 4(3): p. 1112.

23. Shine S, et al. Prevalence and Associated Factors of Stunting among 6-59 Months Children in Pastoral Community of Korahay Zone, Somali Regional State, Ethiopia. Journal of Nutritional Disorders and Therapy, 2017. 7: p. 1.

24. John B et al. Predictors of stunting in children aged 6 to 59 month: A Case-control study in Southwest Uganda. Food and Nutrition Bulletin, 2017. 38(4): p. 542-553.

25. Jago C. Natural selection and sex differences in morbidity in early life. J Theor Biol, 2000. 202(1): p. 65-76.

26. Dara W, Deska S, and Gusnedi. Risk factors in the event of stunting children aged RI 24-59 months (case study in Kelurahan Balai Gadang health center of air dingin Padang city in 2015). Riau International Nursing Conference, 2015.

27. Abuya BA and C.K. Effect of mother's education on child's nutritional status in the slums of Nairobi. BMC Pediatrics, 2012. 12: p. 80.

28. Dayu $\mathrm{K}$ et al. Influence of infant feeding practices on nutritional status of under-five children. Indian journal of pediatrics, 2006. 73.

29. Bhagowalia P, et al. "What dimensions of womens empowerment Matter Most for child Nutritio? : Evidence using Nationally Represenatative Date from Bamgladesh.". International Food Policy Research Institute, 2012: p. 1-21.

30. Paudel R, et al. Risk Factors for Stunting Among Children: A Community Based Case Control Study in Nepal. Kathmandu Univ Med J, 2012. 39(3): p. 18-24.

31. UNICEF. Programming Guide Infant andYoung Child Feeding Nutrition Section, Programmes. May 2011.

32. Batiro $B$, et al. Determinants of stunting among children aged 6-59 months at Kindo Didaye woreda, Wolaita Zone, Southern Ethiopia: Unmatched case control study. PLOS ONE, 2017. 12(12).

33. Park K, et al. Trends and determinants of undernutrition among young Kenyan children: Kenya Demographic and Health surve; 1998,2003 and 2008-2009. Public Health Nutrition, 2012. 15(9): p. 1715-1727.

\section{Supplementary Files}

This is a list of supplementary files associated with this preprint. Click to download.

- S1Surveytool.docx 